\title{
Using an Online Personality Assessment Tool to OPTIMIZE FIRST-YEAR ENGINEERING DESIGN TEAMS
}

\author{
Chirag Variawa, Julie Murphy, Albert Wong \\ Northeastern University, CLUES Software Associates \\ c.variawa@neu.edu; julie@clues.ca; albert@akwglobal.com
}

\begin{abstract}
This paper discusses a Canadian-made online cloud-based personality assessment tool, and its application in a first-year engineering design course at a large private US university. The motivation for this study is to develop an automated approach to maximizing diversity during team formation at the first-year level, while encouraging learning about differences in personality and their effect on teams. The study found that the CLUES software being used was a step towards greater understanding of differences, and that students who used the knowledge of personality during the team formation phase reported a greater sense of inclusivity.
\end{abstract}

Keywords: Teamwork, Teaming, Groups, Automated, First-year, Engineering.

\section{INTRODUCTION}

Engineers are often required to work together in agile design teams to solve complex problems. Their ability to communicate and to contribute their perspectives may help indicate whether a team is effective in achieving their goals.

As instructors, we can help engage students in authentic learning experiences by helping them learn about leveraging differences in work styles, instead of focusing on a 'one-size-fits-all' approach. By nature, authentic contexts may include features that favour some students over others - those with more background in a context can be better situated to understanding specific problems. Differences among team members may result in communication-related barriers that decrease team cohesion and, as a result, team performance within these contexts. However, as our learning population diversifies, the need to engage all students in accessible learning becomes an increasingly central theme. In an effort to promote diversity in teams, and student participation, we can help optimize team dynamics to emphasize differences in perspectives.
In addition to creating accessible learning environments, some instructors are looking for alternative ways to determine the composition of student teams in engineering classrooms. As many institutions rely on problem-based learning as a pedagogical instrument in first-year, instructors are increasingly called upon to set teams of a particular number of students. The criteria used to determine such teams, especially in first-semester of firstyear, varies significantly based on purpose. But, if that purpose is to maximize diversity, then we may be able to use research to help set these teams.

In some institutions, instructors rely on personality tests and behavioural classifiers like the Myers Briggs Type Index (MBTI) to bin students into specific categories. An extension of these tests would be to make them accessible through an online portal so that students can understand their own - and their peers - personality types to help selfselect diverse teams.

A growing concern in first-year engineering design at Northeastern University in Boston, Massachusetts is to research alternative strategies to team setting. In particular, instructors here were curious to see if a customized firstyear engineering type indicator, based off of MBTI and other research, could be used in the context of a classroom. In their search, they partnered with an organization called CLUES to design, deploy, and analyze the effectiveness of one such alternative personality-test instrument.

\section{WHAT IS CLUES?}

\subsection{Description of Approach}

This study employs an automated research-based algorithm, CLUES, that classifies student personalities to mitigate performance barriers that may be present in team projects. CLUES is based Jungian theory and the further development of this theory by Myers and Briggs.

The assessment looks at how students think, learn best, communicate and whether they are more naturally structured or flexible, comfortable with significant change. The tool identifies core strengths and uncovers areas where 
there could be potential challenges. The nomenclature is unique and memorable, the identifying characteristics simple, making it easy for students to ascertain work-styles of other members.

The tool also provides specific advice for effective communication with other styles and how to leverage personality traits by assigning roles that fit with style.

The study looks at individual team member's attributes and then how they can come together with others to execute projects, capitalizing on all the strengths of the team members'. Particularly, it gives individuals some information on which they can base decisions for team selection. It should be emphasized that there is no perfect personality style, and no prescribed method of making effective teams - the implication here is that the individual will take the information from CLUES about personality style, and form a team based on maximizing diversity in those styles. As such, there is an in-class instruction component to using this system which is imperative to this system being deployed in the classroom.

\subsection{Description of Software}

CLUES is a cloud-based personality assessment tool, administered through an internet browser. It helps instructors automatically map-out personal work and learning styles of the students within their class. These assessments allow instructors and students understand their personality traits and can provide guidance and strategies to better assign roles, communicate and work collaboratively with other team members.

This software assigns each user one of four personality types. In the classroom, knowledge of these personality types can potentially encourage students to favour diversity in team formation, that is based on something other than just MBTI values. Particularly, the onus of assigning diverse teams shifts from the instructor to the student, as an instruction to maximize quantifiable personality indices is more formulaic and strategic than simply instructing students to form their teams implusively. The goal is to educate students so that they can identify different personality types, and eventually form diverse teams without instructor assistance.

\subsection{Specific indices of CLUES}

The CLUES program assigns the user to one of four categories: Visionary, Experiencer, Traditionalist, and Inspirer.

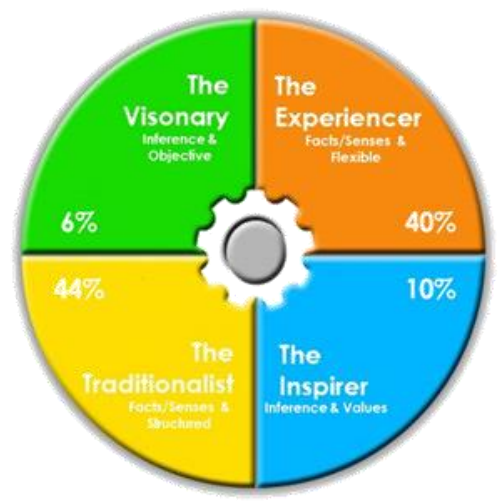

Figure 1 - Shows the four personality types in the CLUES program

Visionary people are creative problem solvers who naturally see flaws and inefficiencies and want to fix them. These individuals see the big picture and anticipate trends. Their rational style may be seen as somewhat abrupt and insensitive to others who are more sensitive.

Experiencers are categorized as being resourceful men and women of action. They thrive on adventure; they can be impulsive, risk takers, who are more comfortable with constant change, often bored when things are too routine. Hands on learning are ideal for these students. These individuals often end up enjoying careers in the essential service sector, PR or sales.

Traditionalists generally are dependable, focused, structured and results driven. They can be the ultimate project managers; detailed, organized individuals who will get the job done on time. They need facts, detail and stepby-step instruction so often do very well in the traditional school setting. In teams they may get frustrated when things change or other members are not as buttoned down as they are.

Inspirers are often the team motivators; concerned about how others are getting along. They too are driven by problem-solving, but they focus on challenges that affect people or values. Although sometimes, overly sensitive, they are often the glue in teams, ensuring that outcomes consider the impact on people as well as the bottom line.

Additionally, CLUES explores two other essential personality style characteristics: 1 . how individuals think, learn best, which is also the basis of how they communicate. Do they think best "out-loud," exploring thoughts with others to draw conclusions and remember, or do they need to "reflect," spending time to digest information and develop thoughtful conclusions. This is a critical component that sets CLUES apart. Identifying this characteristic within individuals allows team members to communicate in a way that optimizes how material is 
absorbed and thinking output. It is also a vital element to be considered when teaching and developing student learning. 2. how people operate; are they structured, needing order, wanting a conclusion at almost any cost or are they flexible, meeting change well, but light on delivering on time and in a clear, step-by-step way?

As each user is issued their specific personality type, they are also given instruction on the unique attributes of the other personality types. Together with self and peerpersonality information, students are equipped with a quantifiable way to potentially maximize the effectiveness of team formation and teamwork.

\section{METHODOLOGY}

\subsection{Description of Approach}

Step 1 - Instruction to class about personality and its role in team work

The instructor spends a class period discussing the role of research in team work, and how diversity of skills is a feature that adds to the breadth and depth of thought. Through various in-class activities, students begin to learn that working with people involves understanding their personality and background (academic, experiential, etc). The learning outcome of this 'infused lecture' is to help students learn about how tools like CLUES can help people form teams with greater diversity.

Step 2 - CLUES Online Assessment

Each student takes the 11 minute, 44 question online assessment and instantly receives their downloadable, personalized report that details their work-style (Traditionalist, Visionary, Inspirer, or Experiencer), communication style (think out loud or reflective) and their operating style (structured or flexible). The report also details their strengths, potential blind-spots and advice based on their personal characteristics. The report teaches the students ways to recognize other styles and how to work with those styles. The report includes a section on career opportunities, with a focus on matching roles that fit their style.

The professor instantly receives a summary report that both maps the personality styles of his/her students and provides group insights that can be used to customize teaching approaches and used to select teams for team development projects.

\section{Step 3 - Project 1 Team Selection by Professor}

There are three major design projects in the first-year engineering design course used to administer the CLUES software. Each of these design projects had teams set by the instructor.
To organize the groups, a matrix was developed to assist in getting a good mix of different work styles:

a. Age - ideally we wanted a mix of ages

b. Gender - a fair mix of all genders within the teams.

c. Personality styles from CLUES (Each team should have someone who is an Inspirer; a Visionary; an Experiencer; and a Traditionalist)

Table 1 - EXAMPLE: Shows a sample composition for an 8-person student group

\begin{tabular}{|l|l|}
\hline \multirow{2}{*}{$\begin{array}{l}\text { Age } \\
23-22\end{array}$} & Examples \\
\cline { 2 - 2 } $23+$ & 5 \\
\cline { 2 - 2 } $\begin{array}{l}\text { Gender } \\
\text { Female } \\
\text { Male }\end{array}$ & 3 \\
\hline Inspirer & 4 \\
\cline { 2 - 2 } & 4 \\
\hline Visionary & 2 \\
\hline Experiencer & 2 \\
\hline Traditionalist & 2 \\
\hline
\end{tabular}

Each team is provided with an individual team summary report that focuses on their team composition. It identifies the work-styles, communication styles of the group along with advice that offers the team ways to optimize the productivity of the group by suggesting ideal roles by style. Eg. Traditionalists are typically good project managers, detail-oriented, good at scheduling etc.

The team then organizes themselves and executes the required class project together, within the time period.

At the end of this exercise, the team is asked the following: Who becomes a leader? Under what circumstances? When is a particular style most helpful to the team? Did the team find that they were able to be more efficient with this division of labor? An attribution table, detailing each student's contribution(s) to the project, is completed to rate individual member's contributions to the project. Marks are assigned accordingly within the overall evaluation of the project.

Step 4 - In-class quiz - the learning objective is to reinforce identification of the key attributes that are assigned to each style.

Step 5 - Project 2 Team Selection by Professor The professor again assigns individuals to teams, with a different mix of individuals but using similar methodology: selecting a good mix of different work styles. Step 3 is repeated, again. 
Step 6 - Project 3 Team Selection by Students

Now, the students will pick their own team members. The list of class members with identified work-style is posted to facilitate selection. Following the grouping, students will be asked to rationalize their selection choice. The signup sheet will include name and work-style.

Again, each team is provided with an individual team summary report that focuses on their team composition. Teams are self-selecting.

Step 7 - Peer-evaluation

Students are asked for their feedback on the CLUES system, and whether and to what extent it helped them form effective teams.

Students are asked, during a peer-evaluation of other groups during a final oral presentation assignment, to estimate the personality types of the student presenters.

The self-reported CLUES personality type for each presenter is compared to the peer-estimated personality type to see if there is any correlation between the two. Here, the peer-evaluators cannot ask the presenters what their personality types are. The goal here is to see if the audience (the peer-evaluators) can detect personality type accurately, without assistance from the course instructor.

Additionally, the course instructor then compares group performance (indicated by grades) to diversity of personality types within the teams. Here, the goal is to see whether diverse teams, according to the CLUES software, have higher overall scores on assignments.

Some of the questions that motivate this study include: Did random, student selected team work as well as the selected teams? Was there a change in student confidence working in a team setting by the end of the course? And, was their evidence of remembering styles by the end of the course?

\section{OUTCOMES AND CONCLUSIONS}

Students who participated in this exploratory study reported to feel more confident when selecting team members for first-year engineering design classes. On the first day of class, many students appeared to be alienated by the first-year student experience - being in a large room with many new faces was not something that some students felt comfortable with. Though there were some exceptions, many students felt that working with teams at such an early point in the school year would be difficult, since they did not know each other quite well.

Introduction to the CLUES program, and theory behind teamwork, helped students become more aware of the different ways that teams function. Many students reported having worked in teams in their previous schooling (and other experiences), but they did not report having any theoretical background for how effective teams are formed and how they would function. Using a critical perspective, the class felt that knowing more about their team members strengths and weaknesses, and even working tendencies (structured vs. flexible) would be useful to effective teamwork.

Of particular interest is that some students reported that such knowledge would be useful to them, but reverted back to an unstructured way of forming teams during some initial in-class low-stakes learning activities. When asked why, students said that because the nature of the activity was to complete a task in a short period of time (in about 45 minutes), they did not have enough time to refer to the CLUES system to think about personality and its role in teaming. Instead, they prioritized time to completion.

However, for larger design projects that spanned several weeks, the students did use the CLUES system to maximize diversity of personality within each team. Increasingly, students were able to more accurately infer the personality types of their peers according to this system over the duration of the course. For the final presentation assignment, a summative assessment, students were asked to voluntarily identify the personality type of the speakers presenting the material in an unaided manner. Here, students were often accurate in gauging the personality styles. This would indicate that using the CLUES system could be a potential tool in helping students form teams, as they can begin to see the value of diversity in first-year design teams.

Though this is an exploratory study, it shows that learning about teamwork with a software tool can help students choose greater diversity in first-year teams - and this is a step towards greater inclusivity where all students are valued for their contributions.

\section{Acknowledgements}

The authors would like to thank Dr. David MacCoy for his insight and experience with this project. 